\title{
THE GREEN ECONOMY, HEALTH CO-BENEFITS OF CLIMATE CHANGE MITIGATION STRATEGIES
}

\author{
By \\ El Samra GH \\ Department of Occupational and Environmental Medicine, \\ Faculty of Medicine, Cairo University.
}

\begin{abstract}
:
Climate change has become a problem that received global interest in a world that strives to achieve sustainable development. Sustainable development and climate change mitigation lie within the domain of Green Economy which stresses low carbon development and conservation of resources. This article deals with health co-benefits of climate change mitigation strategies in the context of green economy and in the light of the mitigation strategies recommended by the IPCC (2007).

Health effects of climate change were discussed. These included: the effects of heat waves; effects on the basic requirements for health: clean air and water; adequate food and shelter. There was increased air pollution; increased activity and multiplication of pathogens resulting in increase of air- and water-borne diseases including diarrhoeal diseases and cholera; extension of vector-borne diseases including malaria to new areas due to the effect on the disease vectors; the effects of extreme weather events : wind storms resulting in death, injury and damage of property; floods causing drowning and contamination of drinking water with sewage, industrial and agricultural waste; and drought. Agricultural production will be affected with resulting malnutrition. Posttraumatic stress follows extreme weather events. Forced migration due to floods and sea level rise causes deterioration of hygiene ; sanitation ; health services, and economic and social conditions.

Health co-benefits are discussed in 3 sectors: housing, health facilities and workplaces. In the housing sector, the subject is discussed under 3 headings: i. housing contribution to climate change; ii. effect of climate change on the housing environment and human health and iii. housing and human health risks including environmental health risks (indoor air quality risks; extreme thermal conditions; pests and infestations; noise; and urban form and density) diseases and injuries in residential buildings (T.B. and other air-borne infectious diseases; vector-borne diseases; water-borne diseases and diseases due to water scarcity and sanitation; domestic injuries; mental health; sick building syndrome and other building-related diseases).
\end{abstract}


In the health care facilities, water and energy needs are huge, and the sector contributes a sizeable proportion of Green House gases (GHGs). Greening hospitals will participate in the efforts for mitigation and health care buildings that participated in the "Leadership in Energy and Environmental Design" programme achieved reduction in energy consumption in addition to health benefits. Mitigation strategies involved the areas of structural specification of buildings; sitting; renewable energy; water management; waste management; recapture and reuse of anaesthetic gases, tele-health; better managed procurement policies and green areas.

Mitigation strategies in the workplaces referred to the "Green Job Initiatives" and stressed protection of the health of workers and the community; study of the health effects of new materials and new processes before they are put to operation and the preventive and control measures for hazards at the workplaces. Several industries were discussed: renewable energy (solar; wind; hydropower; biomass; marine wave and tidal energies and geothermal energy); waste management and recycling; mining; agriculture and construction and renovation industries. Hazards of each industry were outlined and control measures were suggested.

Key words: Climate change, Mitigation, Green economy, Green jobs, Renewable energy, Green house gases.

\section{Introduction}

Challenges confronting the world during the $21^{\text {st }}$ century include effects of climate change, depletion of natural resources and-at the same time-having to achieve sustainable development based upon economic development, social justice and environmental protection.

In his endeavour to achieve sustainable development and improve his standard of living, man has achieved numerous positive outcomes, but there were also negative results, important among which was climate change.

Climate change mitigation is action to decrease the intensity of radiative forces in order to reduce the effects of global warming.

The United Nations Environment Program defined the Green Economy as “ A System of Economic Activities Related to the Production, Distribution , Consumption of Goods and Services that Results in Improved Human Wellbeing over the Long -term, while not Exposing the Future Generations to Significant Environmental Risks and Ecological Scarcities"(UNEP,2011) .

Green economy has also been defined as based on six main sectors:

1. Renewable energy (solar, wind, hydropower, bio-energy, wave and tidal energy and geothermal energy). 
2. Green buildings (energy and water efficiency; green products and materials and leadership in energy and environmental design).

3. Clean transportation (alternative fuels, public transport, hybrid electric cars, carsharing and carpooling programs).

4. Water management (water reclamation; grey water and rain water systems; low-water landscaping and storm water management).

5. Waste management (recycling, municipal solid waste salvage and sustainable packaging).

6. Land management (organic agriculture; habitat conservation and restoration; parks and soil stabilization).

Thus defined, green economy meets the objectives of climate change mitigation, and, in its simplest expression, green economy can be thought of as "one which is low carbon, source efficient and socially inclusive " (UNEP,2008).

The UN defines climate change mitigation as human intervention to reduce the sources or enhance the sinks of Green House Gases and to remove greater amounts of $\mathrm{CO}_{2}$ from the atmosphere (Wikepedia, 2013).

Change of the climate of Planet Earth has drawn so much interest. Several meetings were held at various levels: local , regional and international , to study the phenomenon and try to predict the range of effects on earth if human activities continue at the same level, which activities are the cause of the problem.

In spite of the fact that the climate of earth undergoes natural cyclic changes where periods of warmth alternate with ice ages; these changes occur over hundreds of thousands of years. It was observed, however, that during the last few decades, climate has undergone accelerated changes resulting from an increase of the average temperature of the planet. Researches have pointed to the fact that these accelerated changes were due to an increase in the concentration of certain gases in the atmosphere as a result of human industrial, agricultural and domestic activities among which gases are carbon dioxide, methane, nitrous oxide, chlorofluorocarbons and hydrochlorofluorocarbons among others. These gases are known as the "Green House Gases (GHGs)". 
Effects of climate change (CC) on ecological systems are mostly negative; only a few are positive. Climate change affected agricultural activities, water resources, biodiversity, marine ecosystems, tourist activities as well as human settlements; it affects the basic requirements for health : clean air and water; sufficient food and shelter.

Researches, predictions and observations pointed to the fact that $\mathrm{CC}$ will have marked negative effects on human health. In the early nineties of the 20th century, health effects of CC were not precisely known. However, reports of the Intergovernmental Panel on Climate Change (IPCC) in 1996 and 2001 pointed to the fact that certain effects of $\mathrm{CC}$ have repercussions on human health. The IPCC report of 2007 reaffirmed the fact that "In general CC is expected to increase the negative health effects especially in poor communities and in tropical areas"; the "Working Group III " in the report recommended several steps for mitigation of $\mathrm{CC}$ (IPCC,2007).

Among the health effects of CC are: (McMichael et al., 1996):

1. Increased frequency of heat waves with consequent attacks of heat exhaustion, heat cramps and heat stroke. Increased air temperature leads to increased morbidity and mortality especially among the elderly and those suffering from cardio-respiratory illnesses.

2. Increased concentration of air pollutants: winds increase total suspended particles; increased temperature enhances the formation of photochemical oxidants ; increased air temperature interferes with convection currents which are operative in diluting the concentration of air pollutants; and increased concentration of pollens which results in increased frequency of asthmatic attacks.

3. Increased activity and multiplication of pathogens in warm climates results in increased frequency of air- and water-borne diseases. Many of the major killers are climatesensitive to temperature and rain fall including cholera and diarrhoeal diseases.

4. Expansion of the geographic distribution areas and increased activity of disease vectors, intermediate hosts and certain parasites. Geographic distribution of malaria will expand due to expansion of the geographic distribution of the 
mosquito. Warmer temperature, higher humidity and more places where fresh water can collect favour malaria transmission.

5. The frequency, severity and geographic sites of extreme weather events (wind storms, tornadoes, floods and drought) will increase.

6. Floods cause drowning, physical injuries and heighten the risk of diseases transmitted through contamination of drinking water due to mixing with sewage, agricultural and industrial waste with consequent increase of cases of intoxication and water-borne disease. They increase the risk of diseases transmitted through insect vectors and rodents; damage homes; and disrupt the supply of essential medical and health services.

7. The effects of drought are particularly severe in areas that are already water-stressed. It increases the risk of water and food shortages and malnutrition. Drought will result in increased concentration of pollutants in water, and will increase the risk of diseases transmitted through contaminated food and water. Also, man may have to use low quality water; and there will be an increased frequency of waterwashed diseases like trachoma and scabies. The combination of extreme heat and drought is also an important risk factor for wildfires resulting in direct death, economic losses and increased risk of respiratory illness due to smoke pollution (WHO, 2009).

8. Wind storms cause death, illness, injury, psychological impact and destruction of health facilities and health services (WHO, 2009).

9. Agriculture will be affected due to reduction of water for irrigation, inundation of fertile land due to sealevel rise and the effect of CC on vegetations as well as increased pest population. Resulting malnutrition will affect growth and intelligence of children and reduce productivity of adults.

10. Migration of population due to sea-level rise and extreme weather events will lead to overcrowding at the new sites and deterioration of hygiene and environmental health.

11. Post-traumatic stress syndrome may follow extreme weather events.

12. Increased temperature of marine water may affect the fish catch and 
result in increased growth of types of poisonous algae in coastal water which may reach man through fish and crustacia.

13. Sea-level rise and consequent higher level of ground water will lead to inundation and salination of fertile soil, and will hamper the disposal of sewage which will flood streets and contaminate drinking water with consequent increased incidence of water-borne diseases.

14. Displacement of population due to sea-level rise, floods or destruction of agricultural system results in deterioration of social structure and of the economic resources which affects the livelihood and health of the population. Displaced groups may compete over dwindling or degraded natural resources (water resources, fertile land, shelter etc....) with increased risk of conflict or war .

Health is an essential element of sustainable development. A healthy person can learn, produce and be more useful to his community. Moreover, sustainable development leads to improvement of health since it leads to a better standard of living, thus man can be more productive and more useful to his community.
In the IPCC report (2007), Group III recommended a number of technologies for $\mathrm{CC}$ mitigation for use in different sectors (IPCC,2007). These will be summarised as follows :

Energy supply: Improved supply and distribution efficiency; fuel switching from coal to gas; nuclear power and renewable sources.

Transport: More fuel-efficient vehicles; cleaner diesel vehicles; shift from road transport to rail; public transport systems; cycling and walking; land use and transport planning.

Buildings: Efficient lighting and day lighting; more efficient electrical appliances, heating and cooling devices; improved insulation and solar energy for heating and cooling.

Industry: More efficient electrical equipment; heat and power recovery; material recycling and substitution and control of non-CO2 and GHG emissions.

Agriculture: Improved crop and grazing land management to increase $\mathrm{CO} 2$ storage; restoration of degraded land; improved rice cultivation technologies; livestock and manure management to reduce methane emissions; improved nitrogen fertilizer 
application technologies to reduce nitrous oxide emissions; energy crops and improved energy efficiency.

Waste: Landfill methane recovery; waste incineration with energy recovery; composting of organic waste; controlled waste water treatment; recycling and waste minimization.

\section{Change in lifestyle and} behaviour patterns can contribute to $\mathrm{CC}$ mitigation across all sectors. Management practices can also have a significant role as indicated :

- Reduction of GHG emissions; consumption patterns that emphasize resource conservation and contribute to developing a low-carbon economy that is both sustainable and equitable.

- Education and training can ensure acceptance of energy efficiency.

- Reduction of $\mathrm{CO}_{2}$ emissions related to occupant behaviour; cultural patterns; consumer choice and use of technologies.

- Urban planning that can reduce the need for travel; and information that can reduce car use and lead to more efficient driving style.
- In industry: staff training, efficient management and regular feedback can reduce energy use and GHG emissions.

- Health co-benefits from reduced air pollution as a result of actions to reduce GHGs can be substantial.

It is the general consensus that, even if whatever changes in the climate are due merely to natural phenomena caused by geophysical causes - man not having to do with them, $\mathrm{CC}$ mitigation will in all cases lead to improvements in the environmental condition and that the " No Regrets Policy “ will lead to positive results in a number of areas, whether the phenomenon of $\mathrm{CC}$ is true or false.

This article will deal with " Health Co-benefits of CC Mitigation Strategies " in a number of selected sectors :

- Housing

- Health facilities

- Workplaces

I. Health Co-benefits of Climate Change Mitigation Strategies in the Housing Sector (McMichael et al.,2003):

The importance of $\mathrm{CC}$ mitigation in the housing sector is emphasized in 
the $4^{\text {th }}$ report of the IPCC (2007) which states that residential and commercial buildings have the greatest potential for reducing GHG emissions costeffectively within a short time using available technologies. At the same time, housing and the built environment have a profound impact on human health. This article will deal with the topic under three headings (McMichael et al.,2003) :

1. Housing contribution to climate change

2. Effect of climate change on the housing environment and human health

3. Housing and human health risks :

- Environmental health risks related to housing

- Diseases and injuries in residential buildings .

\section{A. Housing contribution to climate change :}

Residential buildings contribute to climate change in several ways :

1. Residential buildings are significant sources of GHGs. Carbon dioxide is a product of energy supply to houses as are domestic activities like cooking and heating. Methane results from decomposition of organic matter and $\mathrm{CO} 2$ results from burning of organic waste.

2. In developing countries, mid- and high- density housing tend to be more energy-efficient than lowdensity housing of comparable size and standards. Residents of denser settlements are likely to have lower per-capita emissions than those of low density areas as a result of building and urban efficiencies e.g. greater use of public transport systems. However, in developing countries where the per-capita income is high and where electric power is available, even in suburbs and rural areas, housing in high density areas may be less energyefficient.

3. Horizontal expansion of cities where centres for residential and commercial services are situated at long distances and where those areas are difficult to serve with public transport, more use of the private car generates more GHGs, causes more pollution, more noise and more accidents.

B. Effect of climate change on the housing environment and human health : 
1. Protection of residential buildings from extreme weather events necessitates proper sitting and proper selection of building materials and construction styles which give the buildings more resistance to extreme weather events.

2. Heat island effect, which refers to the disparity between urban and periurban temperatures, is particularly acute during heat waves . This is the consequence of large unbroken expanses of built areas; poor sitting and design; disappearance of green spaces, and large expanses of asphalt-paved areas which absorb heat energy and release huge amounts of heat radiation. Heat island effect is a major factor of heat stress and reinforces reliance on air conditioning with more GHG emissions.

3. Extreme weather affects indoor housing environment through patterns of direct and diffuse sunlight; air temperature ; air movement and relative humidity. These factors change with change of climate, and depend on the site, density of buildings, age of building, building materials and energy system; and determine air quality, respiratory health, and vulnerability to growth of moulds and bacteria in humid climates.

4. Passive design is recommended. This depends on the utmost use of sun light; choice of building materials; the surface area of the building which permits occupants to enjoy the quality of indoor air and topography which permits utmost degree of comfort.

5. Safe household, clean drinking water and sanitation are integral to healthy housing environment. These can be affected by climate change. In coastal areas and areas subject to flooding, sea level rise and flooding can disrupt sewage systems which increases the risk of bacterial dispersion, contamination of water resources and outbreaks of water-borne diseases. Also higher ambient temperatures increase bacterial growth in drinking water systems.

6. Provision of a sound water infrastructure is more energy- and cost-efficient.

7. When drinking water resources are degraded orinclimate-related impact such as drought, energy required 
for continued water extraction and purification will present an increase in energy demand thus increasing GHG emissions.

8. Population growth and rising standard of living increase demand on clean water resources and sanitation services. They also increase the amount of methane from solid waste. Therefore, proper water management, proper design of sewage systems can reduce energy required for treatment and GHG emissions.

\section{Housing and human health risks :}

Climate change mitigation strategies affect - directly and indirectly - health of household occupants. Therefore, it is important to be familiar with health risks inside the home and to take in consideration the relationship between health and the environment in the house when dealing with $\mathrm{CC}$ mitigation strategies.

Health risks can be defined in terms of psychological risks, physiological risks, risk of infection and risk of injury. They will be discussed under the following headings:

1. Housing-related environmental health risks :
- Indoor air quality risks (indoor smoke; relative humidity and moulds; radon, chemical pollutants and Volatile Organic Compounds (VOCs); asbestos and lead ).

- Extreme thermal conditions.

- Pests and infestations.

- Noise.

- Urban form and density.

2. Housing-related diseases and injuries :

- Tuberculosis and other air-borne infectious diseases.

- Vector-borne diseases.

- Water-borne diseases and diseases due to water scarcity and poor sanitation.

- Domestic injuries.

- Mental health.

- $\quad$ Sick building syndrome.

- Other building-related illnesses.

\section{Housing-related Environmental} Health Risks :

a. Indoor Air Quality Risks: Low ventilation rates result in increased concentration of pollutants. Dependence on natural ventilation 
will also increase the concentration of pollutants if the outside air is highly polluted.

\section{i. Indoor smoke from household heating and cooking:}

Indoor smoke is the second most important environmental health risk (after water

pollution and poor sanitation). It affects especially women and children. Most important sources are burning of coal, solid fuel, bio-mass, and kerosene stoves. Indoor smoke predisposes to a number of diseases including pulmonary infection especially in children, COPD, cancer of the lung , upper respiratory tract infection, asthma and heart disease. Polluted out-door air can penetrate the house and intensify the problem. Smoking and burning incense increase the problem. Smoking is the leading cause of preventable disease and pre-mature death and incense may result in neurological symptoms.

Death due to $\mathrm{CO}$ poisoning can result from the use of gas or kerosene heaters in badly ventilated space.

\section{ii. Relative humidity and moulds:}

Active growth of micro-organisms and excessive accumulation of biological agents in the indoor environment is often due to high relative humidity, inadequate ventilation and inappropriate occupant behaviour. Moulds, fungi, bacteria, bacterial spores, fragments, and pollens may be present in damp, ill-ventilated spaces. Dampness is more likely to occur in over-crowded houses where there is lack of appropriate heating, ventilation or insulation.

\section{iii. Radon, volatile organic compounds (VOCs) and chemical pollutants:}

These pollutants can be present in air-tight buildings for energy efficiency. This must be controlled by proper ventilation, and control of emissions. Radon emanates from some building materials. Soil gas infiltration is the most important source of residential radon. Radon causes a high percentage of cases of lung cancer. It is heavier than air; therefore, it affects residents of the lower floors of buildings.

VOCs include formaldehyde which causes irritation and cancer of the upper respiratory tract. Other organic chemicals may cause sensitization and bronchial asthma. The source may be building materials; furniture; paints and carpets ; smoking and detergents. Mercury may contaminate the indoor environment from fluorescent lights and thermostats. 
The risk here can be reduced by natural ventilation and the use of healthier building materials and furniture.

\section{iv.Asbestos and other natural mineral}

\section{fibres :}

Asbestos is a carcinogenic material used for heat, fire and sound insulation; in pipes; boilers; ceiling tiles and roofing. When building materials using asbestos deteriorate or are damaged, they release asbestos dust and fibres. Asbestos causes cancer of the lung, pleura and larynx.

\section{v. Lead :}

Prolonged exposure to lead affects the nervous system, blood and some other body systems. In children, it affects cognitive function, intelligence and leads to abnormal behaviour. The use of lead in buildings has been largely reduced; it had been used in lead pipes, and in paints. In the outdoor environment, most countries have banned the use of lead in gasoline.

\section{b. Extreme thermal conditions :}

Indoor thermal factors are major determinants of cardiovascular and respiratory diseases. Thermal conditions are linked to poorly insulated, poorly ventilated and poorly heated buildings as well as poor social conditions.

Heat waves result in heat exhaustion, heat cramps and heat stroke; and death which is essentially due to cardiovascular disease especially among the elderly. The effect is more marked the longer the duration of exposure. There is an association between mortality and isolation and the housing condition.

Cold-related illnesses affect mostly the elderly and victims of cardiorespiratory disease, especially in winter. Among the main building-related determinants of cold indoor air are: age of the building (the older the colder), poor heating system, low household income and the size of the building (the smaller the colder). Overcrowding, lack of exposure to sunlight and indoor pollution are important determinants of disease risk.

\section{c. Pests and infestations :}

Urban sprawl, irresponsibly discarded trash, international travel and $\mathrm{C} \mathrm{C}$ are all factors caused by human behaviour that increase human exposure to pests and pest-related diseases. Moreover, characteristics of the building are important factors 
in the multiplication of pests; poor maintenance such as broken floor tiles, damaged water pipes and overflowing cisterns are examples. Mistaken design and construction can provide favourable conditions and places for pest multiplication and increase the incidence of diseases caused by allergic reactions to pests, their body parts or excreta. Cockroaches and house dust mites are among the most relevant pest antigens. House dust mite is a known cause for bronchial asthma, and high relative humidity is favourable for its presence. Adequate insulation and ventilation can reduce the incidence of diseases caused by these allergens and other pollutants.

\section{d. Noise :}

Noise causes sleep disturbances; affects the cardiovascular and nervous systems and causes annoyance and reduced productivity. High levels of noise cause hearing impairment. Exposure of children causes cognitive defects and reduced ability of learning. In addition to irresponsible use of media, traffic noise, air conditioners, density of buildings, commercial centres, aeroplanes and industry are common causes of environmental noise.

\section{e. Urban form and density :}

Links between neighbourhood and physical activity have become a focus of recent health research. Proper design which provides enough spaces between buildings for sport and recreation, green areas and parks facilitate free and safe movement of children and favour their healthy development. Women, the elderly and the disabled also enjoy these conditions; they have the chance to indulge in physical activity and light sport which improves their health and protects them from diseases caused by physical inactivity as obesity and increases social ties between residents of the neighbourhood. Less dependence on private cars and encouraging commuting by walking or cycling are also beneficial and necessitate provision of sidewalks, lanes for bicycles and a good road network.

Inhabitants of slums suffer a number of problems like low income, less chances for education, malnutrition, overcrowding, pollution, stress, traffic problem , transportation difficulties and poor sanitation which lead to a number of physical, psychological, social and moral problems. In slums, there is high incidence of diarrhoeal diseases due to lack of clean water; tuberculosis 
and respiratory diseases due to overcrowding, pollution, inadequate ventilation and high relative humidity which favours the growth of moulds and mites; and vector-borne diseases like malaria; in addition to road accidents.

\section{Housing-related Diseases and}

\section{Injuries :}

\section{a. Tuberculosis and other air-borne infectious diseases :}

By the end of the 19th century and the beginning of the 20th century it became evident that there was significant association between the incidence of tuberculosis and housing density, income level, ventilation and sanitation. Improvement in the treatment of the disease together with improvement of the housing environment resulted in significant reduction in the prevalence of the disease. However, during the last decades of the 20th century, the incidence of the disease has increased significantly. It was evident that the emergence of T.B. bacilli resistant to anti-tuberculous drugs together with housing density, low income levels, poor ventilation, lack of sunlight and marginal health care services were among the causes of this increase.
It was clear also that the same housing problems have resulted in increased incidence of a number of infectious respiratory diseases like influenza. Artificial ventilation is an important factor in spreading infection in buildings; buildings depending on natural ventilation suffer less from these diseases than central air-conditioned, over-crowded buildings.

An example of infectious diseases related to buildings is legionnella pneumonia where the organism multiplies in cooling, humidification and air-conditioning systems and in house dust.

Systemic fungal infection is another example which spreads in the same way.

\section{b. Vector-borne diseases :}

Climate change through the effect of expanding the geographic range of distribution of disease vectors, resulted in extension of vector-borne diseases to new areas; an example is malaria. Extension of such diseases is also affected by movement of the people and changes in the host and pathogen. Rapid unplanned urbanization can provide mosquito breeding sites and human population density provides a larger pool of susceptible individuals. 
Buildings play an important role in direct and indirect spread of disease. Housing design can provide sites for breeding of vectors or can impede vector entry through well maintained window screens, or closed windows or the use of mosquito nets. Cracks in the walls or certain building materials can provide vector habitat. Protection of water storage containers, avoiding close proximity to domestic animal breeding sites and human behaviour are important in protection.

\section{c. Water-borne diseases and diseases due to water scarcity and poor sanitation:}

Provision of clean water and sanitation are the foundations of a healthy housing environment, and are essential in control of diarrhoeal diseases and other water-borne diseases. During floods, drinking water systems and sanitation are threatened and flood can disperse faecal material and contaminate water and food leading to outbreaks of water-borne diseases like cholera and diarrhoeal diseases.

Drought can result in acute water shortages leading to more diarrhoeal diseases, and to water-washed diseases like trachoma and scabies.
Therefore, at household level, provision of facilities for good hygiene, sanitary disposal of excreta, the use of safe materials for water pipes, safe water storage and hygienic behaviour are critical to control of water-borne diseases.

Energy-efficient technologies must be used in extraction, treatment and transport of water along with household water conservation.

\section{d. Domestic injuries :}

A WHO study of 4 low- income countries found that $65 \%$ of childhood burns and most drowning and poisonings occur in or around the house (McMichael et al.,2003).

Along with human behaviour, poor design and maintenance of the house are leading causes for domestic injury. This can include poor design of gas and electrical installations; steps and stairs; widows and balconies on upper floors; slippery floor material; poor lighting; noise exposure and crowding.

\section{e. Mental health :}

Mental health is directly affected by environmental health. It was observed that inhabitants of slums suffer more from mental and social problems. In slums, there is overcrowding, poor 
ventilation, lack of clean water, poverty, unemployment, illiteracy and unsanitary conditions. Therefore, physical, mental and psychosomatic diseases are more prevalent .

Post-traumatic stress syndrome may follow extreme weather events.

\section{f. Sick building syndrome (Kreiss, 2007) :}

This is a combination of symptoms including eye, nose and throat irritation; headache; fatigue and less frequently dry and itchy skin. The characteristic of the syndrome is its tight temporal association with building occupancy and the rapid resolution of symptoms within minutes or hours after the affected office workers leave the implicated building, except perhaps for skin symptoms. The syndrome is distinguished from the more medically serious building-related illnesses by its subjective nature, reversibility and the high incidence within the implicated building and across the non-industrial sector.

The syndrome is more prevalent among women, smokers and those working in front of computers.

The actual cause of the syndrome is not known. Various studies have pointed to certain factors that characterize the sick building :

- Cooling, humidification and airconditioning; and high relative humidity favour the growth of micro-organisms and fungi and the air-conditioning system helps their distribution within the building.

- Low ventilation ratecauses increased concentration of pollutants in air.

- Dust from carpets and upholstery may contain fungi or toxins of gram-negative bacteria especially when relative humidity is high.

- Pollutants like dust from construction sites and certain pollutants which emanate from building materials or furniture like formaldehyde and VOCs.

- It has also been mentioned that the incidence of the syndrome is higher among building occupants who suffer from exhaustion or dissatisfaction with their work.

g. Other building-related diseases (Kreiss, 2007) :

These include hypersensitivity pneumonitis and bronchial asthma. They may occur sometimes in the same sick buildings among those who do not 
suffer from the syndrome. They are more serious, have definite signs and symptoms, and the offending exposure should be stopped.

Hypersensitivity pneumonitis occurs in buildings where contaminated water spray is used for cooling or where the air-conditioning system is contaminated. It can also occur in buildings where water leaks and reaches carpets or furniture which will then provide a suitable medium for growth of bacteria and fungi.

Building-related bronchial asthma is more common than hypersensitivity pneumonitis. Among the causative factors is high relative humidity in the buildings where air-conditioners or humidifiers are used, which favours the growth of bacteria and fungi.

High relative humidity causes also sinusitis and rhinitis which can precede the development of asthma.

Other building-related diseases also include (Blanc,2007) :

- Inhalation fevers.

- Pontiac fever which affects a high percentage of occupants who are sensitive to Legionnella organisms which grow in air-conditioning systems.
- Humidifier fever which is attributed to toxins of bacteria growing in air-conditioning systems and humidifiers.

It should be taken in consideration that not all CC mitigation strategies have the same effect on health; some are beneficial while others may cause unseen health risks if enough studies are not carried out to evaluate the effects before they are adopted so that control measures may be included. For example, thermal insulation in cold areas interferes with proper ventilation which favours spread of air-borne infections like T.B., and increases the concentration of pollutants. On the other hand, in hot climates, depending on natural ventilation should be accompanied with means to protect against mosquitoes by using screens on windows and openings and nets over beds.

\section{Health Co-benefits of Climate Change Mitigation Strategies in the Health Care Facilities (WHO,2011) :}

Hospitals provide their services all day long, and every day. Modern health care facilities - in order to provide preventive and curative services need a number of energy-intensive 
procedures in the areas of lighting, heating, cooling, air conditioning, sterilization, waste management and transport. Hospitals use more than double the energy consumption of administrative buildings. They also need large amounts of clean water, and generate large amounts of waste estimated in the USA at 7 thousand tons per day, $20-30 \%$ of which is operating room waste which contains toxic and infectious materials. Studies in the USA have shown that the health care sector produces $8 \%$ of the GHGs of the country. Therefore, $\mathrm{C} \mathrm{C}$ mitigation strategies which result in more energy efficiency, less water consumption and more efficient waste management will lead to more economic use of health care resources both in the short-term and in the long-term and lead to better health care coverage.

This article deals with the health cobenefits of $\mathrm{C} \mathrm{C}$ mitigation strategies for the health care sector. These strategies will enable the health care service system to participate in the efforts for mitigation, to deal more efficiently with consequences of climate change and to deliver better services more equitably to areas not served before.
Studies have also been carried out on the direct effects of mitigation strategies on the health care delivery system and their environmental and occupational effects on health care workers, patients and the community at large.

In accordance with these efforts and with the growing interest in conservation of energy and natural resources, there developed interest in spreading the idea of the green economy in the health care delivery system which materialized early during the 20th century. In 2002, the "American Society of Health Care Engineering " framed " Green Building Initiatives " which aimed at the conservation of natural resources and protection of the health of building occupants and the community. With the introduction of the "Green Guide for Health Care" and the US Green Building Council's voluntary “ Leadership in Energy and Environmental Design (LEED) ", studies indicated that health care buildings that followed the LEED principles achieved a reduction in energy consumption of $15-30 \%$ in addition to the health care co-benefits (USEPA,2014).

This article is based mainly upon the $\mathrm{C} \mathrm{C}$ mitigation strategies in the 4th report of the IPCC (2007) in relation to 
industry and the commercial buildings since the health care service sector was not included in the report. Mitigation strategies applicable to the health care sector, their impact on GHG emissions, health co-benefits, limitations and needs are given in the WHO publication on "Health in the Green Economy" (WHO,2011). Strategies and

health co-benefits are summarized in the following :

a. Observing sound structural specifications in hospital buildings, stressing full use of sunlight, natural ventilation and thermal insulation which ensures energy efficiency.

b. Sitting of health care facilities near major transport routes and safe pedestrian and cycling routes ensures reduction of GHGs through reduction of the use of private cars.

c. The use of clean on-site energy generation (renewable energy) ensures more reliable energy supply in areas where frequent energy outages occur and in emergencies.

d. Health risks to health care workers, patients and the community will be reduced by improved management of waste and so will the GHG emissions and toxic emissions resulting from poor incineration processes like dioxins, and will reduce exposure to toxic chemicals, infective waste and radioactive waste.

e. Large quantities of water and water treatment are required for many health procedures. Many rural health facilities lack piped water; in these areas water management is important to reduce health risks. Energy efficiency in extraction and treatment of water, conservation of resources and conservation in the use are important. Harvesting rain water is an important source in certain areas.

f. Anaesthetic gases, in addition to their direct health effects (Nervous System., liver and reproductive effects), are among the powerful GHGs. Therefore, recapture and reuse of waste anaesthetic gases have health benefits and are part of the mitigation strategies .

g. Well designed tele-health schemes can reduce the travel-related carbon foot print of health care and also improve access and outcome for vulnerable groups and remote areas. Mobile phones have been used in some emergency situations and in consultations in remote areas, and 
have been useful in caring for the elderly and patients with diabetes and heart and lung diseases as well as in high risk pregnancy and labour.

h. Better managed procurement of pharmaceuticals and medical supplies saves energy in getting rid of items not used and thus reduces GHG emissions, and reduces workers' exposure to toxic chemicals and their waste products.

i. Procurement of hospital supplies and supplies for health service units from local suppliers saves energy used in transportation. The same applies for food supplies like fresh vegetables and fruits from nearby dealers.

j. Development of simple low-energy or no-energy medical devices like those that use solar energy as LED lights and lanterns; LED microscopes for improved diagnosis of T.B. and solar-powered DC refrigerators for vaccine storage. These devices can improve services in areas with poor energy resources.

k. Green areas around the hospital building help in removing $\mathrm{CO} 2$ and also to improve the mental health of patients.
The health services sector is in the position of leadership to provide a good example in climate change mitigation, control of GHG emissions, conservation of resources and in demonstrating how these efforts can lead to significant improvement of the health of the community.

\section{Health Co-benefits of Climate Change Mitigation Strategies in Workplaces (ILO,2012) :}

Several industries are directly involved in achieving the objectives of C C mitigation

strategies. In 2012 the United Nations Environment Program, the International Labour Organization, the International Organization of Employers and the International Trade Union Confederation launched the "Green Job Initiative". The initiative supports efforts by Governments, employers and trade unions to promote, in a climatechallenged world, environmentally sustainable and coherent policies and effective programs aimed at generating "Green Jobs " and decent work for all.

A green job has been defined as “ decent work which contributes directly to reducing the environmental impact of enterprises, economic sectors or the 
economy as a whole by reducing energy and resource consumption; reducing emissions, waste and pollution and by preserving and restoring ecosystems. Among the pre-requisites, decent jobs need to offer safe working conditions" (ILO,2012).

Recently the notion of green job has been broadened from the protection of biodiversity and the environment to include creation of jobs that contribute to resource efficiency, low-carbon development in green sectors as well as occupations which play a role in greening industries. Greening the existing industries is an important element in sustainable development which at the same time depends upon safe and healthy workplaces for all workers.

Technological progress and economic development have always been dependent on cheep energy. Production and transport activities rely principally on fossil fuel although it became evident that $\mathrm{CO} 2$ and methane are among the GHGs. Also, modern technologies, economic and employment conditions together with population growth necessitate adopting development policies and production technologies which have low energy consumption and smaller environmental carbon footprint .

Mr. Juan Somafia, Director General of the ILO (2012) stated that " The mounting cost of energy-intensive production and consumption patterns are widely recognized. It is timely to move towards a high employment lowcarbon economy. Green jobs hold the promise of a triple dividend : sustainable enterprises, poverty reduction and a job-centred economic recovery" (ILO,2012).

Providing a safe and healthy work environment and protecting the general environment are two sides of the same coin. Measures to reduce the adverse impact of workplaces on the general environment can also protect the local communities, and are major contributions to greening enterprises and the economy .

Awareness of the impact of new and emerging risks linked to green jobs is necessary.

Technologies and processes in green jobs must be the subject of hazard and risk assessment and management, preferably in the design and pre-operational phases. There is an opportunity to guarantee from the onset 
that green jobs are safe and healthy for workers and at the same time minimize negative impact on the environment and communities. The incorporation of preventive and control measures at the design stage is crucial to eliminate occupational hazards and risks associated with " green " technologies.

The replacement of some substances harmful to the environment by more environmentally friendly ones has proven to be less hazardous to workers' health.

This article will discuss some industries which have the best potential for generating new green jobs, these are (ILO,2012) :

- Renewable energy

- Waste management and recycling

- Mining

- Agriculture and

- Construction and renovation .

\section{Renewable Energies :}

With the rapidly rising interest in $\mathrm{CC}$ mitigation, more investment is expected to be seen in renewable energy. This sector includes solar energy; wind energy; hydropower; bioenergy; marine wave and tidal energies and geothermal energy. Solar, wind, hydropower and biomass energies are the most commonly used. Renewable energy establishments provide more jobs than fossil fuel powered power plants for the same amount of energy produced and its cost.

\section{a. Solar Energy :}

Solar energy can be converted to electricity using :

- Photovoltaic (PV) panels or

- Concentrating solar power (CSP).

PV systems are the most common and use semiconductors and sunlight to generate electricity. Occupational hazards exist in the manufacture, installation and eventually end-of-life waste disposal of PV panels. More than 15 hazardous materials are used in the manufacture of PV panels, in addition to the cleaning agents (ILO,2012). At the end of their useful life, PV panels present a hazard of the electronic waste which contains a number of toxic elements ( cadmium, tellurium and gallium arsenide ); these may be hazardous to workers and the environment. Installation workers face physical hazards similar to those in construction work which may include falls from heights, high temperature, confined spaces and electrocution. 
There are hazards of exposure to toxic fumes to fire-fighters and residents in case of fire in buildings involving PV panels.

Concentrating solar energy uses the sun rays to heat a receiver which creates mechanical energy to generate electricity. Occupational hazards are faced in construction, and maintenance of installations such as electrical hazards, high temperature and hazards from concentrated sunlight.

\section{b. Wind Energy :}

Types of jobs involved include project development, turbine manufacture, installation, operation and maintenance.

Hazards in the manufacture are similar to those in the automobile industry and aerospace installations; while hazards in installation and maintenance are similar to those in construction work. Workers may be exposed to chemicals like epoxy resins; styrene and solvents; toxic gases and vapours; and dusts and to physical hazards from moving parts as well as manual handling in blade manufacture and maintenance. Physical hazards in the manufacture include falls from heights, musculoskeletal disorders, physical load, electrocution and injuries. Risks also involve exposure to fibreglass and hardeners. Health problems include dermatitis, dizziness, sleepiness, liver and kidney damage, blisters, chemical burns and reproductive problems.

\section{c. Hydropower :}

Hydropower is the most important renewable energy source for electrical power production. It provides more than $17 \%$ of the world's electricity. The environmental impact of hydropower is related to the damming or lowering of the water level; changes in water flow or building of dams, roads and power lines. Small-scale hydropower installations do not have the same kind of environmental effects as the large ones. Hazards and risks associated with construction, operation and maintenance of large hydropower stations include mechanical injuries, electrical hazards, and chemical hazards from sulphur hexafluoride gas and polychlorinated biphenyls. Safety measures and protective equipment should be provided and emergency response should be in place.

\section{d. Bio-energy :}

Bio-energy is developing fast. It includes liquid bio-fuels, biogas 
and modern biomass for heating and power generation. Future technological development of bio-fuels will take into account a wide range of energy crops for bio-ethanol and bio-diesel, such as algae, jatrova and used cooking oil/ animal fats. One major concern is the impact of using land to grow energy crops. There is rising concern over bio-energy contributing to rising food prices, loss of biodiversity and failure to reduce carbon emissions.

Hazards of bio-energy production are related to feedstock production and are similar to those in agriculture: exposure to agrochemicals; hazards of manual harvesting; physical load and hot and humid environment. During thermal processing there is exposure to toxic gases, carcinogenic substances, CO, NOx, lead, VOCs, dioxins and trace amounts of heavy metals. During storage, biomass presents a fire risk when dry; there is a risk of explosion when small particles are dispersed in air. Biomass can also produce local air pollution, spores and foul liquids which can affect health.

\section{Waste Management and Recycling :}

Most waste management strategies promote a shift from considering waste as unwanted burden to viewing it as a valued resource, or to prevent its generation in the first place.

Methane may evolve from waste accumulations and auto-combustion can generate huge amounts of $\mathrm{CO}_{2}$. Therefore, recycling will be an important step in industrial processes and in waste management. However, recycling technologies may introduce new risks to health. New materials when collected as waste may present a variety of hazards like nanomaterials, chemicals and electronic waste. Recycling work can be dirty, polluting, undesirable and dangerous. There can be exposure to various hazards like mercury from light bulbs; scrap metal and broken glass as a cause of injury; heavy metals; repeated trauma disorders; skin and respiratory diseases; infectious hospital waste; toxic industrial waste as well as electronic waste. When waste is used to generate energy it can generate hazards from toxic gas production, explosion and dangerous chemicals.

Waste pickers are usually vulnerable, poor and poorly paid even in developed countries.

\section{Mining :}

Mining operations may expose workers to injury; fires and explosion; 
electrocution; heat and humidity; mercury and other chemicals and silicosis.

Environmental impact of mining includes the emission of methane, $\mathrm{CO} 2$ and nitrous oxide; and the use of fuels, power and plenty of water. The environmental and health impact of mercury is well known; when released, mercury can travel long distances and be deposited on soil and in lakes.

\section{Agriculture :}

Sustainable agriculture foresees the integration of environmental health, economic viability and social equity as well as the management of natural resources. It also promotes reduction in the use, substitution or elimination of agrochemicals, the use of watersaving irrigation and enrichment of soil with organic material. It also aims at reduction of methane and nitrous oxide emissions. Organic agriculture has achieved most of these goals. However, it is more labour-intensive and less productive than commercial agriculture.

Although occupational hazards and risks in agriculture are similar, future application of biotechnology presents new risks.

\section{Construction and Renovation :}

Construction is one of the most hazardous occupations in which occupational safety and health proves to be an essential element. Green construction work has many occupational risks similar to risks in traditional construction such as work at heights; use of hand and power tools; electricity; confined spaces and handling of chemicals. The introduction of renewable energy equipment at heights, new construction materials such as insulation materials and paints containing nanomaterials can be sources of hazard and risk.

Exposure to lead and asbestos in demolition and renovation work is particularly hazardous.

In general, greening industry requires adhering to occupational health and safety principles as well as those of environmental protection in all stages from planning to manufacturing and operating stages to the use of safe technologies and equipment; and should observe principles of recycling. In new buildings, energy-efficiency should be observed as well as the use of safe and environmentally friendly building materials. 


\section{References}

1. Blanc PD (2007): Inhalation fever, in, Rom, W. N., ed., Environmental and Occupational Medicine, 4th ed., Lippincott, Williams and Wilkins. New York, London. Pp 402-17.

2. Epstein PR (2005): Climate change and human health. The New Eng J Med; 333: 1433-6.

3. International Labour Organization (2012): Promoting safety and health in a green economy. World Day for Safety and Health at Work. International labour Organization. Geneva.

4. Intergovernmental Panel on Climate Change. Fourth Assessment Report (2007): Working Group III: Mitigation of Climate Change. Bangkok.

5. Kreiss K (2007): Sick building syndrome and building-related illness, in, Rom, W. N., ed., Environmental and Occupational Medicine, 4th ed., Lippincott, Williams and Wilkins. New York, London. Pp. 1373-80.

6. McMichael AJ, Campbell-Lendrum DH, Corvalan CF, Ebi KL, Githeko AK, Scheraga JD and Woodward A (2003): Climate change and human health. Risks and responses. World Health Organization, Geneva, 10-109.

7. McMichael AJ, Haines A, Slooff R and Kovats S (1996): Climate Change and Human Health. World Health Organization, Geneva. Pp 50-160.
8. Nerlander L (2009): Climate change and health. Commission on Climate Change and Development. Stockholm, Sweden.

9. United Nations Environment Program (2011): Green Economy Initiative. Meeting on Economic Policies Supporting the Transition to a Green Economy. Regional preparatory meeting series for Rio+20. Beirut, Lebanon.

10. UNEP-led (2008): Green Economy Initiative.

11. United states Environmental Protection Agency (2014): the United States Green Building Council's leadership in Energy and Environmental Design.

12. Wikepekia, the Free Encyclopaedia (2012): Climate change mitigation, available at en.Wikepedia.org/climate_change_mitigation.

13. World Health Organization (2009): Protecting the health of vulnerable people from the humanitarian consequences of climate change and climate related disasters. Sixth session of the ad hoc working group on long-term cooperative action under the convention (AGW-LCA6). Bonn.

14. World Health Organization (2011): Health cobenefits of climate change mitigation - Housing sector. World Health Organization. Geneva.

15. World Health Organization (2011): Health in the green economy. Co-benefits to health of climate change mitigation. Health care facilities. World HealthOrganization. Geneva. 